\title{
EVALUATION OF ANTIOXIDANT PROFILE AND PHYTOCHEMICAL CONSTITUENTS OF SOME HERB-SUPPLEMENTED BLACK TEA INFUSIONS
}

\author{
GARGI CHAKRABARTIª, SANCHITA BHATTACHARJEEa, SAURYYA BHATTACHARYYA ${ }^{*}$ \\ aDepartment of Food and Nutrition, Sarada Ma Girls' College, Talikhola, Barasat, Kolkata 700126, India \\ Email: sauryya.b@gmail.com
}

Received: 28 May 2017 Revised and Accepted: 02 Nov 2017

\section{ABSTRACT}

Objective: The present study was designed to adjudicate the change in contents of phytochemicals and in vitro antioxidant potential of tea infusions supplemented with herbs.

Methods: The phytochemical screening of tea infusions with or without supplemented herbs was done along with their antioxidant capacities using some common in vitro assays. Infusions were prepared by soaking tea leaves and subsequent herbs in boiled water for 10 min.

Results: 2,2'-azinobis(3-ethylbenzothiazoline-6-sulfonic acid) (ABTS) radical scavenging ability did not improve after herb supplementation of the infusions, although 2,2'-diphenyl-1-picrylhydrazyl (DPPH) radical scavenging ability improved in some samples, especially in ginger tea. This proves that less polar phytochemicals are supplemented mostly when herbs are added in the tea infusions. Tannin contents were mostly preserved except for the ginger tea. The most prominent effect was observed in their hydroxyl radical scavenging abilities, which commensurate with the lipid peroxidation inhibitory activities of the supplemented infusions.

Conclusion: Present study provides firm evidence to support that an augmenting effect exists between black tea and some supplemented herbs when infusions were prepared with the both.

Keywords: Tea, Camelia sinensis, Antioxidant, Tannins, Flavonoids

(C) 2017 The Authors. Published by Innovare Academic Sciences Pvt Ltd. This is an open-access article under the CC BY license (http://creativecommons.org/licenses/by/4.0/A DOI: http://dx.doi.org/10.22159/ijpps.2017v9i12.20318

\section{INTRODUCTION}

Beverage is composed chiefly of water used as a drink for the purpose of relieving thirst and introducing fluid along with some biomolecules to the body, nourishing the body and stimulating or soothing the individual. Consumption of tea as a beverage is associated with reduced risks of cardiovascular disease and cancer, and health effects of tea come from its high content of phytochemicals with antioxidant activity [1]. The tea plant is an evergreen shrub of the Camelia genus, native to India and China, with dark green shiny leaves and white flowers. Camelia sinensis var. sinensis and Camelia sinensis var. assamica are the two varieties most frequently used for the production of different types of tea. Tea and/or tea polyphenols have been found to inhibit cancers of the skin, lung, oral cavity, esophagus, stomach, small intestine, colon, liver, pancreas, and mammary gland in animal models [2]. However, the results of human studies-both epidemiologic and clinical studies-have been inconclusive. Tea is also valued for its taste, aroma, health benefits, and cultural practices.

The manufacturing processes impart profound changes in the phenolic compound profile of tea, with respect to individual compounds as well as in the antioxidant capacity of final tea products. Many of the compounds are lost a few new compounds are generated during oxidizing procedures. One important group of biomolecules is theabrownins, probably produced along with the microbial production of celluloses and pectinases [3].

During the process of fermentation, the simple polyphenols undergo enzymatic polymerization resulting in the formation of condensed compounds. The red color of tea and its astringent property is due to these polyphenols, and the astringency is lowered when we add milk due to the formation of casein complex [4-5]. Consequently, the antioxidant potential of milk tea is much reduced. In recent years there has been more and more research on the effect of consumer preparation on composition and activity of tea infusions [6-7]. The studies have examined the different culinary methods used in the domestic preparation of tea infusions, taking into account factors such as water temperature, infusion time, stirring and usable forms like loose-leaf tea and tea bags.

Earlier studies indicated that antioxidant and pharmacological activities of green tea could be enhanced by adding lemon juice, which might be explained by the effect of ascorbic acid on the increased stability of polyphenols due to lowered pH [8]. The study opened a new era of research where tea additives were supposed to play an important role to offset the deterioration of tea during processing.

A very common tea preparation method in Indian households, using ginger, black pepper and tulsi were found to be beneficial as assessed by in vitro DPPH assay [9]. Tea supplemented with lemon juices is also consumed greatly in India, probably to lower the astringency of the infusion. Lemon supplemented tea was also found to be better that tea without lemon in some in vitro assays [10].

The present study is thus an attempt to evaluate and document antioxidant profile and phytochemical constituents of tea infusions supplemented with different herbs. These herbs are used in tea preparations for centuries in India. The study is probably the first to indicate an improvement of the quality of tea infusions for human consumption after supplementation of the herbs. This has been achieved by some common in vitro antioxidant assays.

\section{MATERIALS AND METHODS}

\section{Chemicals}

2,2'-azinobis(3-ethylbenzothiazoline-6-sulfonic acid), ABTS, were obtained from Sigma, India. 2,2'-diphenyl-1-picrylhydrazyl (DPPH) were obtained from Himedia, India. Analytical grades of thiobarbituric acid (TBA), ascorbic acid, gallic acid, FolinCiocalteau's solution, sodium hydroxide, ethylene diammine tetraacetic acid (EDTA) and sodium carbonate were obtained from Merck, India. All other reagents and chemicals used were of analytical grade procured from local sources. Deionized distilled water was used in the entire study. 


\section{Preparation of samples}

The samples were procured from local markets of Barasat, Kolkata. The samples were checked for dirt or any visible damages prior to the study. Such samples were discarded. The liquors were prepared by the following procedures -5 gms each of the samples were taken in $80 \mathrm{ml}$ double distilled water, separately, for the preparation of liquor. For clove tea, $100 \mathrm{mg}$ of chopped clove were added during extraction; for lemon tea, $10 \mathrm{ml}$ of lemon juice was added after extraction; for basil tea, $100 \mathrm{mg}$ of chopped basil leaf was added during extraction; for ginger tea, $100 \mathrm{mg}$ of minced ginger was added during extraction; and for cardamom tea, $100 \mathrm{mg}$ of chopped cardamom was added during extraction. After extraction, the samples were centrifuged at $8000 \mathrm{rpm}$ for $5 \mathrm{~min}$. The clear supernatants were used for in vitro antioxidant assays.

\section{ABTS radical decolourization assay}

The ABTS assay was performed using a previously described procedure [11]. The oxidant was generated by persulfate oxidation of 2,2'-azinobis(3-ethylbenzothiazoline)-6-sulfonic acid. This solution was diluted with phosphate buffered saline $(\mathrm{pH} 7.4)$ until the absorbance reached 0.7 to 0.8 at $734 \mathrm{~nm}$. The oxidant solution was mixed with the sample solutions, kept for $4 \mathrm{~min}$ in the dark at room temperature and absorbance was read. All measurements were done with a Systronics spectrophotometer (model-2202). Results were expressed as Gallic acid equivalents ( $\mu \mathrm{g} / \mathrm{ml}$ tea infusion).

\section{DPPH radical decolourization assay}

The DPPH assay was performed using a previously described procedure [11]. DPPH solution $(0.1 \mathrm{mmol})$ was mixed with the sample solution and the decrease in absorbance of the mixture after 20 min of incubation in the dark was monitored at $517 \mathrm{~nm}$ in a Systronics spectrophotometer (model-2202). Results were expressed as Gallic acid equivalents $(\mu \mathrm{g} / \mathrm{ml}$ tea infusion.

\section{Ferric reducing antioxidant power: FRAP}

Ferric reducing the antioxidant power of the samples was estimated with a previously described procedure [12]. Briefly, a maximum of $100 \mu \mathrm{l}$ of extract solution or standard was mixed with $1.9 \mathrm{ml}$ of FRAP reagent and incubated at $37^{\circ} \mathrm{C}$ for $30 \mathrm{~min}$. After the stipulated time period, absorbance was measured at $593 \mathrm{~nm}$ in a UV-Vis spectrophotometer (model-Systronics 2202). Results are expressed as Gallic acid equivalents ( $\mu \mathrm{g} / \mathrm{ml}$ tea infusion).

\section{Estimation of total phenolics content}

Total phenolics compound contents were determined by the FolinCiocalteau method [13]. The samples $(0.5 \mathrm{ml})$ were mixed with diluted Folin-Ciocalteau reagent and aqueous sodium carbonate $(1$ $\mathrm{M}$ ) was added then. The absorbance of the reaction mixture was then measured at $765 \mathrm{~nm}$ in a UV-Vis spectrophotometer (modelSystronics 2202). Results are expressed as Gallic acid equivalents $(\mu \mathrm{g} / \mathrm{ml}$ tea infusion).

\section{Estimation of tannin content}

Total tannin contents were determined by a previously published method [14]. Briefly, $5 \mathrm{ml}$ aliquot of the extract was mixed with 12.5 $\mathrm{ml}$ of indigo carmine solution and $375 \mathrm{ml}$ of distilled water. This mixture was titrated against standardized $\mathrm{KMnO}_{4}$ solution when the blue colour of the indigo carmine changed to yellow with a faint pink tint at the rim. To determine the volume of $\mathrm{KMnO}_{4}$ used to titrate non tannin (related) compounds, another aliquot of the extract was treated with gelatin solution. The mixture was shaken for $15 \mathrm{~min}$ and filtered through Whatman no. 1 filter paper. $12.5 \mathrm{ml}$ of the filtrate was mixed with the same volume of indigo carmine solution and $375 \mathrm{ml}$ of distilled water. This mixture was again titrated against $\mathrm{KMnO}_{4}$ solution until the colour changed to faint pink as earlier. Tannin content was determined by taking the difference between the above two titer values and standardizing the $\mathrm{KMnO}_{4}$ solution with $0.1 \mathrm{~N}$ oxalic acid.

\section{Estimation of total flavonoids content}

Total flavonoid content was determined with a previously described procedure with minor modifications [15]. Briefly $0.5 \mathrm{ml}$ sample was mixed with $2 \mathrm{ml}$ of distilled water and $0.15 \mathrm{ml}$ of aqueous sodium nitrite solution $(5 \% \mathrm{w} / \mathrm{v})$, allowed to stand for $6 \mathrm{~min}, 0.15 \mathrm{ml}$ aqueous aluminium trichloride solution $(10 \% \mathrm{w} / \mathrm{v})$ was added and allowed to stand for another $6 \mathrm{~min}$, followed by addition of $2 \mathrm{ml}$ of aqueous sodium hydroxide $(4 \% \mathrm{w} / \mathrm{v})$ solution. The final volume was made up to $5 \mathrm{ml}$ of distilled water. The reaction mixture was mixed thoroughly and allowed to stand for another $15 \mathrm{~min}$ at room temperature. The absorbance of the reaction mixture was then measured at $510 \mathrm{~nm}$ with a UV-Vis spectrophotometer (modelSystronics 2202). Quercetin was used as a standard. The results are expressed in terms of quercetin equivalent ( $\mu \mathrm{g} / \mathrm{ml}$ tea infusion).

\section{Estimation of monomeric anthocyanin contents}

Determination of monomeric anthocyanin content was conducted by pH-differential method [16]. Total monomeric anthocyanins were expressed as cyanidin-3-glucoside. Sample absorbance was read against a blank cell at $700 \mathrm{~nm}$ and $510 \mathrm{~nm}$ and at $\mathrm{pH} 1.0$ and 4.5 . The absorbance (A) of the sample was then calculated according to the following formula:

$$
A=\left(A_{510}-A_{700}\right)_{\mathrm{pH} 1.0}-\left(\mathrm{A}_{510}-\mathrm{A}_{700}\right)_{\mathrm{pH} 4.5}
$$

Where $A$ is the net absorbance of samples at the wavelengths mentioned in the subscript. The monomeric anthocyanin pigment content in the sample will be calculated according to the following formula:

$$
\text { Anthocyanin content }(\mathrm{mg} / \mathrm{l})=\frac{(\mathrm{A} \times \mathrm{MW} \times \mathrm{DF} \times 1000)}{(\varepsilon \times \mathrm{l})}
$$

Where DF was dilution factor, MW was molecular weight of cyanidin-3-glucoside (449.2), 1 is the path length and $\varepsilon$ was molar absorptivity $(26,900)$. The anthocyanin content in the sample solution was converted into $\mathrm{mmol}$ per gm of tea leaf.

\section{Hydroxyl radical scavenging assay}

Hydroxyl radical scavenging potentials of the samples were estimated with a previously described procedure [17]. Briefly, 10 mmol each of $\mathrm{FeSO}_{4} .7 \mathrm{H}_{2} \mathrm{O}$, EDTA, 2-deoxy-D-ribose and $\mathrm{H}_{2} \mathrm{O}_{2}$ solutions were prepared in water. The reagents and sample and/or standard solution was mixed in a test tube and incubated at $37^{\circ} \mathrm{C}$ for $90 \mathrm{~min}$. After the incubation, $2.8 \%(\mathrm{w} / \mathrm{v})$ aqueous trichloroacetic acid (TCA) solution and $1 \%(\mathrm{w} / \mathrm{v})$ aqueous TBA solution were added to the reaction mixture and kept at boiling water bath for $20 \mathrm{~min}$. Development of the pink chromophore was measured at $532 \mathrm{~nm}$ in a UV-Vis spectrophotometer (model-Systronics 2202). Results are expressed as Gallic acid equivalents ( $\mu \mathrm{g} / \mathrm{gm}$ tea leaf).

\section{Inhibition of lipid peroxidation in vitro}

Method of a previously described procedure was followed with minor modifications [18]. 10\% (w/v) of fresh chicken liver homogenate was prepared using ice-cold $\mathrm{KCl}(0.15 \mathrm{M})$. Lipid peroxidation was initiated by the addition of $\mathrm{FeSO}_{4}$, ascorbic acid and $\mathrm{KH}_{2} \mathrm{PO}_{4}$. The volume was made up and incubated at $37{ }^{\circ} \mathrm{C}$ for one hour.

Then 5\% TCA and $0.67 \%$ TBA in 50\% acetic acid was added to this reaction mixture and heated for $20 \mathrm{~min}$ in a boiling water bath. The extent of inhibition of lipid peroxidation was evaluated by the estimation of the pink chromophore of Thiobarbituric acid reactive substances (TBARS) level by measuring the absorbance at $532 \mathrm{~nm}$. Results are expressed as Gallic acid equivalents ( $\mu \mathrm{g} / \mathrm{gm}$ tea leaf).

\section{Statistical analyses}

Values were expressed as mean \pm standard error of four replicates of each experiment. The analyses were done using the software-SPSS Statistics 17.0 (IBM Corporation).

\section{RESULTS AND DISCUSSION}

Tea has always influenced human health by its vast content of antioxidant bio actives from the time immemorial. A plethora of evidence suggests that tea components including bioflavonoids and tannins are highly effective in scavenging free radicals [19]. However, brewing time and the addition of milk to tea infusions cause a profound reduction in affectivity of the drink [6]. To overcome such shortcomings, tea infusions are often mixed with 
different herbs during or after brewing. As different herbs have different bioactive constituents with different antioxidant activities, the mixtures show better antioxidant capacity than the individual components when mixed together. It might be due to synergistic, additive or antagonistic interaction among different compounds. In depth research also showed that polyphenols like gingerols and their corresponding dehydration products shogaols in ginger and piperine in black pepper are responsible for antioxidant activity in tea preparations in experimental conditions [9].

In the present study, plain black tea had marginally better ABTS scavenging activity over supplemented samples, although the gallic acid equivalence values were very close and fell within the range of standard error (fig. 1). ABTS scavenging efficacy indicates the presence of highly polar biomolecules in the samples [11]. The study indicated that supplementation with herbs did not alter the composition of the polar bioactive in tea infusions. Also, positive ABTS assay results are indicators of involvement of single electron transfer from the antioxidants towards the ABTS radical cation [20]. The results thus indicated the equivalent presence of polyphenolics in all the tea infusions that can be involved in the single electron transfer reactions, which also lent credence to the fact that the bioactive were not destroyed during the preparation of the infusions or by supplementation of herbs.

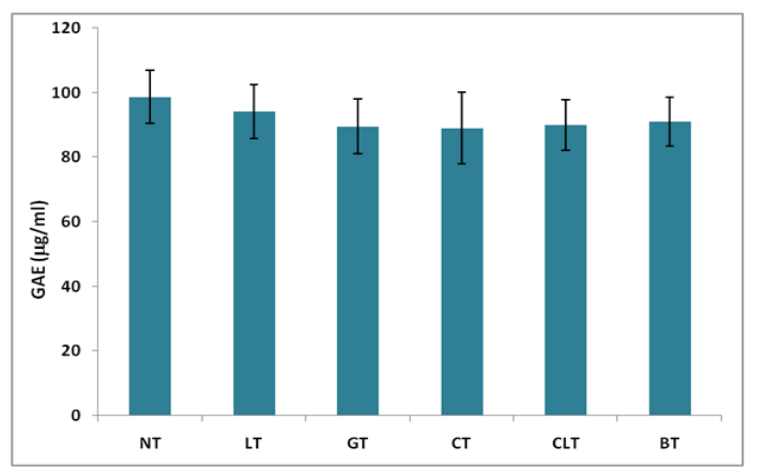

Fig. 1: Comparative ABTS radical scavenging potential of tea infusions in gallic acid equivalents (GAE) with or without added herbs. Data are mean \pm SEM $(n=4)$. NT $=$ Infusion without additive, $\mathbf{L T}=$ Infusion with lime juice, GT = Infusion with ginger, $\mathrm{CT}=$ Infusion with cardamom, CLT = Infusion with clove and BT = Infusion with basil

Unsupplemented black tea has better DPPH scavenging activity over supplemented samples (fig. 2). DPPH scavenging efficacy indicates the presence of less polar biomolecules in the samples [11]. The study also substantiated that supplementation with herbs might reduce the extent of such types of bioactive in tea infusions.

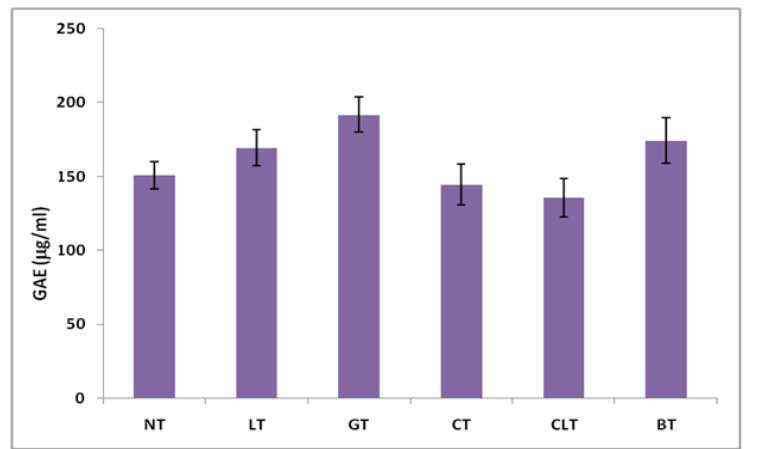

Fig. 2: Comparative DPPH radical scavenging potential of tea infusions in gallic acid equivalents (GAE) with or without added herbs. Data are mean $\pm \operatorname{SEM}(n=4)$. NT $=$ Infusion without additive, $\mathbf{L T}=$ Infusion with lime juice, GT = Infusion with ginger, CT = Infusion with cardamom, CLT = Infusion with clove and $\mathrm{BT}=$ Infusion with basil
It must be noted that reaction of antioxidants with DPPH free radicals are slow, and the rate solely depends on the number of available hydroxyl groups in the polyphenolic antioxidants [20]. The present study indicated that ginger and basil provided antioxidant polyphenols with a large number of hydroxyl groups to the infusions, thereby, probably improving the quality of the preparations.

The FRAP assay indicated that antioxidant properties of some of the supplemented samples were increased (fig. 3 ). This is probably due to the fact that supplemented herbs provide polyphenolics with varied polarities to the tea infusions thereby improving their reducing power.

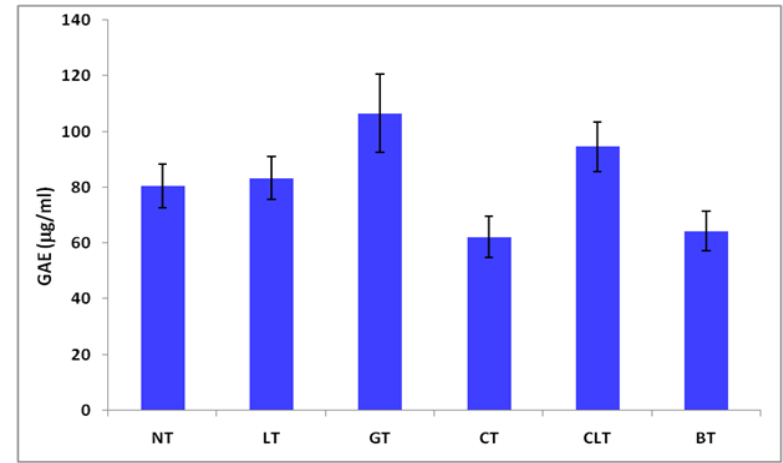

Fig. 3: Comparative FRAP of tea infusions in gallic acid equivalents (GAE) with or without added herbs. Data are mean \pm SEM $(n=4)$. NT $=$ Infusion without additive, $\mathbf{L T}=$ Infusion with lime juice, GT = Infusion with ginger, CT = Infusion with cardamom, CLT $=$ Infusion with clove and BT $=$ Infusion with basil

All of the supplemented tea infusions showed better hydroxyl radical scavenging properties over plain tea infusion. Hydroxyl radical is probably the most deleterious of the systemic free radicals present in humans. The results indicated that supplemented tea infusions could prevent oxidative damage by the above free radical if consumed over plain tea to a greater extent (fig. 4). It can also be seen that supplementation with either ginger, cardamom or clove improved the hydroxyl radical scavenging abilities more than three times. This indicated that supplementation of black tea with these three herbs will be highly beneficial for the consumers.

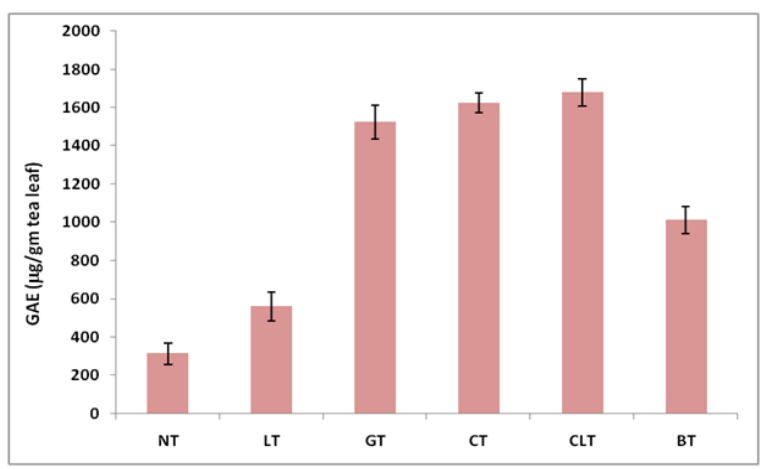

Fig. 4: Comparative hydroxyl radical scavenging potential of tea infusions in gallic acid equivalents (GAE) with or without added herbs. Data are mean \pm SEM $(n=4)$. NT = Infusion without additive, $\mathbf{L T}=$ Infusion with lime juice, GT = Infusion with ginger, CT = Infusion with cardamom, CLT = Infusion with clove and $B T=$ Infusion with basil

Polyphenolic contents of the tea with or without supplements more or less corroborated the results of FRAP assay (fig. 5). Clove tea 
showed most augmented polyphenolic content over others, which commensurate with the result of hydroxyl radical scavenging activity assay. It can be concluded that supplementation with herbs improves reducing potential as well as hydroxyl radical scavenging activities of herb-supplemented tea infusions, probably due to augmentation of different polyphenolics obtained from the additives.

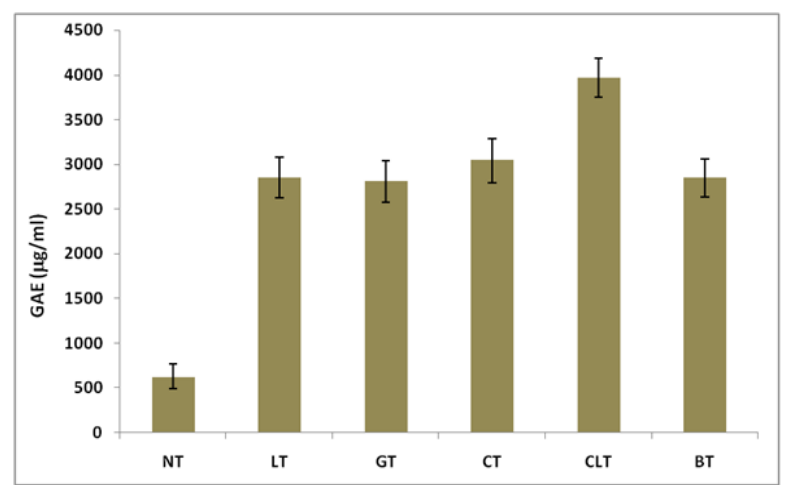

Fig. 5: Comparative polyphenolic contents of tea infusions in gallic acid equivalents (GAE) with or without added herbs. Data

are $\operatorname{mean} \pm \operatorname{SEM}(n=4)$. NT = Infusion without additive, $\mathrm{LT}=$

Infusion with lime juice, GT = Infusion with ginger, $\mathrm{CT}=$

Infusion with cardamom, CLT = Infusion with clove and BT = Infusion with basil

Flavonoid contents in all the supplemented infusions were marginally better than the plain infusion (fig. 6). Most important of them are flavanols, which include catechin and its derivatives [21]. However, in black tea, oxidation of polyphenols during preparation lead to the formation of flavanol-gallic acid complexes like theaflavins, theaflavins acids, thearubigins or procyanidin polymers [22]. The additives might be providing such polyphenols to the infusions, thereby reducing the contents of the flavonoids, as observed in the present study.

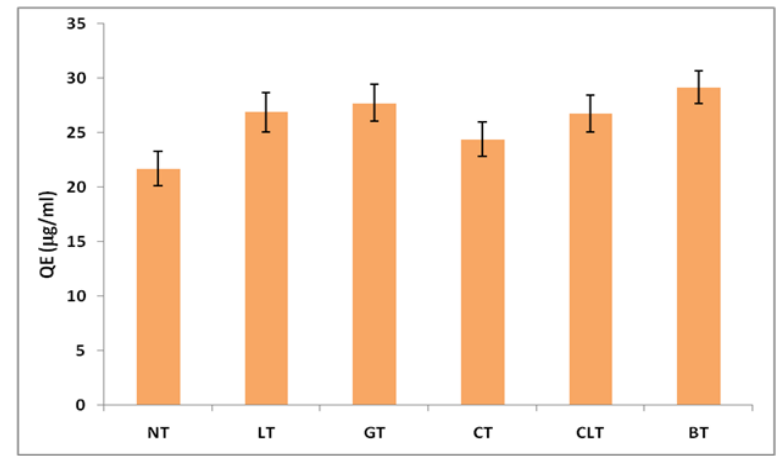

Fig. 6: Comparative flavonoid contents of tea infusions in quercetin equivalents (QE) with or without added herbs. Data are mean \pm SEM $(n=4)$. NT = Infusion without additive, $L T=$

Infusion with lime juice, GT = Infusion with ginger, CT = Infusion with cardamom, CLT = Infusion with clove and BT = Infusion with basil

Tannin content of tea infusions showed a reducing trend when supplemented with herbs and the most prominent effect was with ginger tea (fig. 7). The data indicated that the main bioactive principle of tea, tannins, are neutralized substantially in presence of the supplemented polyphenolics, which also play a key role in reducing the astringency of the infusions, making it more acceptable to people.

It was observed that supplementation of tea infusions with different herbs improved their anthocyanin contents (fig. 8). This is probably due to the fact that herb supplementation lowers $\mathrm{pH}$ of the system thereby stabilizing the otherwise susceptible anthocyanins from oxidative onslaughts.

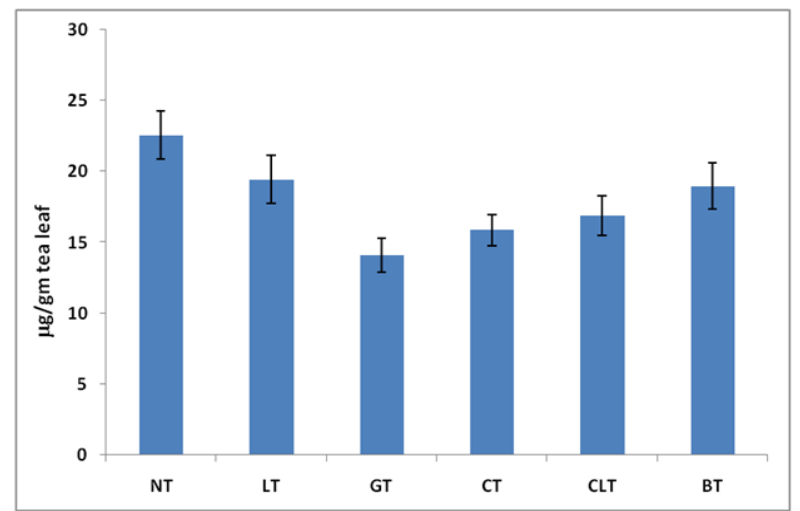

Fig. 7: Comparative tannin contents of tea infusions with or without added herbs. Data are mean \pm SEM $(n=4)$. NT $=$ Infusion without additive, $\mathbf{L T}=$ Infusion with lime juice, $\mathbf{G T}=$ Infusion with ginger, CT = Infusion with cardamom, CLT = Infusion with clove and BT = Infusion with basil

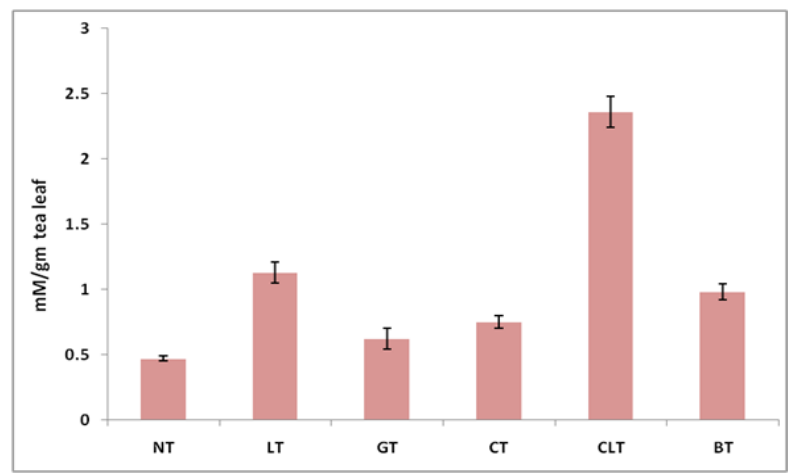

Fig. 8: Comparative hydroxyl radical scavenging abilities of tea infusions with or without added herbs. Data are mean \pm SEM $(n=4)$. NT = Infusion without additive, $L T=$ Infusion with lime juice, GT = Infusion with ginger, CT = Infusion with cardamom,

CLT = Infusion with clove and BT = Infusion with basil

It was interesting to observe that inhibition of lipid peroxidation in in vitro system was improved after herb supplementation of black tea infusions (fig. 9). The results commensurate with the flavonoid contents of the samples (fig. 6), indicating that flavonoids might play some role in the lipid peroxidation inhibiting antioxidant activities of the infusions.

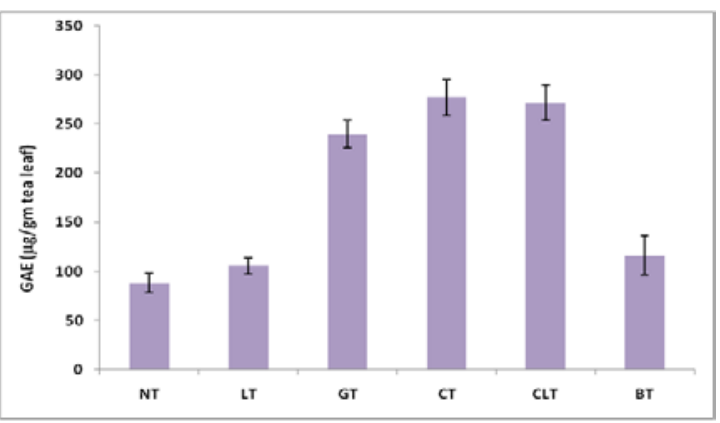

Fig. 9: Comparative lipid peroxidation inhibitory activity of tea infusions with or without added herbs. Data are mean \pm SEM $(n=4)$. NT = Infusion without additive, $\mathrm{LT}=$ Infusion with lime juice, GT = Infusion with ginger, CT = Infusion with cardamom,

CLT $=$ Infusion with clove and BT $=$ Infusion with basil 
The common methods for preparation of tea infusions in the households of India have been shown to be appended with different types of herbs, mostly to reduce the astringency and to augment the radical scavenging abilities as well as in the levels of phytochemical antioxidants. The present study thus lent credence to the fact that addition of such herbal additives might reduce oxidative stress to some extent, which could be helpful for human consumption. This was also partially substantiated by the potentiation of the lipid peroxidation inhibitory properties of the infusions after supplementation.

\section{CONCLUSION}

The present study provided firm evidence to support that quality of herb supplemented tea infusions would be better than the black tea infusion itself. ABTS radical scavenging ability did not improve after herb supplementation of the infusions, although DPPH radical scavenging ability improved in some samples, especially in ginger tea. This proved that less polar phytochemicals are supplemented mostly when herbs are added in the tea infusions. Tannin contents were mostly preserved except for the ginger tea. The most prominent effect was observed in their hydroxyl radical scavenging abilities, which commensurate with the lipid peroxidation inhibitory activities of the supplemented infusions.

\section{ACKNOWLEDGEMENT}

The authors are grateful to Sarada Ma Girls' College authority (under Ramakrishna Vivekananda Mission) for providing financial and infrastructural assistance.

\section{AUTHORS CONTRIBUTION}

Design of the work and preparation of the manuscript was done by Dr. Sauryya Bhattacharyya. Experimental part was done conjointly by Miss Gargi Chakrabarty and Miss Sanchita Bhattacharjee.

\section{CONFLICT OF INTERESTS}

We declare no conflict of interest

\section{REFERENCES}

1. $\mathrm{Fu}$ L, Xu BT, Gan RY, Zhang $\mathrm{Y}, \mathrm{Xu} \mathrm{XR}, \mathrm{Xia}$ EQ, et al. Total phenolic contents and antioxidant capacities of herbal and tea infusions. Int J Mol Sci 2011;12:2112-24.

2. Al Bitar V, Laham S. Methylsulfonylmethane and green tea extract reduced oxidative stress and inflammation in an ulcerative colitis. Asian J Pharm Clin Res 2013;6:153-8.

3. Wang Q, Gong J, Chisti Y, Sirisansaneeyakul S. Bioconversion of tea polyphenols to bioactive theabrownins by Aspergillus fumigates. Biotechnol Lett 2014;9:1-8.

4. Brown PJ, Wright WB. An investigation of the interactions between milk proteins and tea polyphenols. J Chromatog 1963;11:504-14.

5. Rider PJ, Der Marederosian A, Porter JR. Evaluation of total tannins and relative astringency in tea. In: phenolic compounds in food and their effect on health 1. Washington DC, ACS; 1992. p. 103-17.
6. Kyle JAM, Morrice PC, McNeill G, Duthie GG. Effects of infusion time and the addition of milk on content and absorption of polyphenols from black tea. J Agric Food Chem 2007;55:4889-94.

7. Banerjee S, Chatterjee J. Efficient extraction strategies of tea (Camellia sinensis) biomolecules. J Food Sci Technol 2015;52:3158-68.

8. Tewari S, Gupta V, Bhattacharya S. Comparative study of the antioxidant potential of tea with and without additives. Indian J Physiol Pharmacol 2000;44:215-9.

9. Gupta RK, Chawla P, Tripthi M, Shukla AK, Pandey A. Synergistic antioxidant activity of tea with ginger, black pepper and tulsi. Int J Pharm Pharm Sci 2014;6:477-9.

10. Al-Ghafari A, Shorbaji AM, Al-Sarori LA, Baduwailan EO, Basaar AA, Al Doghaither HA, et al. Phenolic contents and antioxidant activities of green tea with and without lemon. Nat Sci 2016;8:247-55.

11. Chakraborty A, Bhattacharyya S. Thermal processing effects on in vitro antioxidant activities of five common Indian Pulses. J Appl Pharm Sci 2014;4:65-70.

12. Aktar N, Rai C, Bhattacharjee S, Bhattacharyya S. Effect of thermal processing on synergistic antioxidant and antimicrobial activities of Turmeric (Curcuma longa) and red chili pepper (Capsicum annuum). Int J Food Nutr Sci 2016;5:19-30.

13. Sarkar S, Saha S, Rai C, Bhattacharyya S. Effect of storage and preservatives on antioxidant status of some refrigerated fruit juices. Int J Curr Microb Appl Sci 2014;3:1007-13.

14. Khasnabis J, Rai C, Roy A. Determination of tannin content by a titrimetric method from different types of tea. J Chem Pharm Res 2015;7:238-41.

15. Pal TK, Bhattacharyya S, Dey A. Evaluation of antioxidant activities of flower extract (fresh and dried) of Saraca indica grown in West Bengal. Int J Curr Microb Appl Sci 2014;3:251-9.

16. Aich-Roy S, Pal TK, Bhattacharyya S. Effect of thermal processing on in vitro antioxidant potential of Capsicum (Capsicum annuum) of different ripening stages. J Pharm Res 2014;8:1751-6.

17. Bhattacharyya $S$, Singha $K$, Rai $C$. Effect of heating resembling cooking on antioxidant profile and phytochemical constituents of malabar spinach (Basella alba) fruits of different maturity stages. Asian J Res Biol Pharm Sci 2016;4:112-21.

18. Jethinlalkhosh JP, Antony A, Praveena P, Doss VAD. Phytochemical, antioxidant, and free radical scavenging activities of a hydro-ethanolic extract of aerial parts of Pothos scandens L. Asian J Pharm Clin Res 2016;9:236-9.

19. Roy $\mathrm{P}$, Bhattacharjee $\mathrm{S}$, Bhattacharyya $\mathrm{S}$. Influence of preparation methods on antioxidant profile and phytochemical constituents of commercial tea (Camellia sinensis) infusions. Int J Food Sci Nutr 2017;2:69-74.

20. Martysiak-Zurowska D, Wenta W. A comparison of ABTS and DPPH methods for assessing the total antioxidant capacity of human milk. Acta Sci Pol Technol Aliment 2012;11:83-9.

21. Hara Y, Luo SJ, Wickremashinghe RL, Yamanishi TV. Chemical composition of tea. Food Rev Int 1995;11:435-56.

22. Chaturvedula VSP, Prakash I. The aroma, taste, color and bioactive constituents of tea. J Med Plant Res 2011;5:2110-24. 